\title{
Coix seed emulsion synergistically enhances the antitumor activity of gemcitabine in pancreatic cancer through abrogation of NF- $\mathrm{KB}$ signaling
}

\author{
YAFANG QIAN $^{1,2}$, BO YANG ${ }^{2}$, YANG XIONG $^{2}$ and MANCANG GU ${ }^{2}$ \\ ${ }^{1}$ Pharmaceutics Preparation Center, Zhejiang Hospital of Traditional Chinese Medicine, Hangzhou, Zhejiang 310006; \\ ${ }^{2}$ College of Pharmaceutical Science, Zhejiang Chinese Medical University, Hangzhou, Zhejiang 310053, P.R. China
}

Received February 2, 2016; Accepted March 10, 2016

DOI: $10.3892 /$ or.2016.4958

\begin{abstract}
Clinical outcomes in patients with pancreatic cancer (PC) continue to be dismal, in part due to de novo and acquired chemoresistance. In the present study, we provide preclinical evidence that pre-treatment with coix seed emulsion, an injectable agent extracted from coix seeds, synergistically sensitized PC cell lines (BxPC-3, PANC-1 and AsPC-1) to gemcitabine, both in vitro and in vivo. Such pretreatment led to significant induction of pro-apoptosis proteins, including caspase-3, cleaved-PARP and Bax $(\mathrm{P}<0.05)$, after lower doses of gemcitabine compared to monotherapy. We also showed that coix seed emulsion suppressed the constitutive and gemcitabine-induced activation of nuclear factor- $\kappa \mathrm{B}(\mathrm{NF}-\kappa \mathrm{B})$, as shown with the use of electrophoretic mobility shift, reporter and immunoblotting analyses. Coix seed emulsion pretreatment also downregulated the NF- $\kappa \mathrm{B}$-dependent anti-apoptotic molecules $\mathrm{Bcl}-2$, survivin and cyclooxygenase-2. In vivo, coix seed emulsion combined with gemcitabine had a much greater antitumor effect than the effect of either agent alone, consistent with the downregulation of the proliferation index, and the results of immunostaining for $\mathrm{Ki}-67$, or for the $\mathrm{NF}-\kappa \mathrm{B}$ subunit p65. Overall, our data demonstrated that coix seed emulsion abrogated gemcitabine-induced activation of $\mathrm{NF}-\kappa \mathrm{B}$, and synergistically sensitized PC cells to gemcitabine therapy.
\end{abstract}

\section{Introduction}

Pancreatic cancer (PC) is a fatal disease. It commonly presents at an advanced stage, with synchronous metastases and poor prognosis. PC has a median survival of 6 months and an overall 5-year survival rate that is less than 5\% (1). PC

Correspondence to: Dr Mancang Gu, College of Pharmaceutical Science, Zhejiang Chinese Medical University, Room 3524, 548 Binwen Road, Hangzhou, Zhejiang 310053, P.R. China

E-mail: gmancang@zcmu.edu.cn

Key words: coix seed emulsion, gemcitabine, synergistic effect, nuclear factor- $\mathrm{\kappa B}$, pancreatic cancer cell lines, in vitro, in vivo is expected to become the second leading cause of cancerrelated deaths in the US within the next decade (2). PC is also highly chemoresistant (3). Currently, the most effective chemotherapies for advanced PC are a combination of 5-fluorouracil (5-FU)/leucovorin with irinotecan and oxaliplatin (FOLFIRINOX) (4), or nab-paclitaxel with gemcitabine, which only provide modest response rates, ranging from 23 to $31 \%$ (5) and have limited tolerability. Thus, discovery of new drugs or drug combination therapies for patients with PC is critically important.

Over the past three decades, a growing number of traditional Chinese medicines have been widely used in China as adjuvant treatments during chemotherapy and radiotherapy for cancer (6). One of the well-known drugs includes the seeds of Coix lacryma-jobi (family Cramineae), which have been widely used as a herbal medicine for the treatment of hypertension, arthritis, cancer and immunological disorders in China $(7,8)$. The oily substance extracted from coix seeds has been prepared in an injectable emulsion form, and has successfully been used in China to treat more than 500,000 patients for various types of cancer, including non-small cell lung (9) and advanced gastric cancer (10), and hepatoma (11). In recent years, the use of coix seed emulsion was tested in the US in a phase II clinical trial for patients with advanced PC $(12,13)$. The results revealed that coix seed emulsion, when combined with gemcitabine, can overcome chemoresistance, increase the tolerance of patients, and significantly improve the lifespan and quality of life of patients. Preclinical studies also indicate that coix seed emulsion blocks the tumor cell cycle at the $\mathrm{G} 2 / \mathrm{M}$ phase (14), and induces tumor cell apoptosis by upregulating the expression of caspase- 8 and downregulating the expression of Bcl-2 and Cox-2 $(15,16)$. However, the mechanisms that underlie the synergistic effect of coix seed emulsion and gemcitabine have not yet been elucidated.

Molecular therapy that is targeted against specific components of defined signaling pathways has recently attracted much attention. Nuclear factor- $\kappa \mathrm{B}(\mathrm{NF}-\kappa \mathrm{B})$ plays a critical role in the development and progression of various human cancers that exhibit constitutive and continuous NF- $\kappa$ B activity $(17,18)$. However, the induction of this signaling pathway is also associated with gemcitabine chemoresistance in PC cells (19-21). We thus reasoned that agents that block NF- $\mathrm{B}$ activation may 
reduce chemoresistance to gemcitabine, and may be effective when used in combination with gemcitabine as a novel therapeutic regimen for treating PC. We demonstrated that coix seed emulsion markedly decreased expression levels of $\mathrm{NF}-\kappa \mathrm{B}$ in the nucleus, and of IkB $\alpha, \mathrm{IKK}$ and EGFR in the cytoplasm of Lewis lung carcinoma in vivo (22). The emulsion also reduced $N F-\kappa B$-dependent reporter activity in a dosedependent manner in MDA-MB-231 breast cancer cells (16).

In the present study, we report on the synergistic action of coix seed emulsion and gemcitabine when both are used in PC cell lines PANC-1, AsPC-1 and BxPC-3, and also in a xenograft mouse model. We also assessed NF- $\kappa \mathrm{B}$ activity and the expression levels of apoptosis-related components that lie downstream of $\mathrm{NF}-\kappa \mathrm{B}$, to explore the mechanism of action of coix seed emulsion plus gemcitabine in treating PC.

\section{Materials and methods}

Antibodies and reagents. Antibodies were purchased as follows: anti-rabbit cyclooxygenase-2 (Cox-2), survivin, Bcl-2, Bax, $\beta$-actin (Santa Cruz Biotechnology, Santa Cruz, CA, USA), cleaved-polyADP ribose polymerase (PARP), Ki-67 and p65 antibody (Cell Signaling Technology, Danvers, MA, USA). Coix seed emulsion (Kanglaite ${ }^{\circledR}$ injection) was obtained from Zhejiang Kanglaite Pharmaceutical Co., Ltd. (Hangzhou, China). Gemcitabine-HCl was purchased from Eli Lilly and Company (Indianapolis, IN, USA). All other chemical reagents were purchased from Sigma-Aldrich (St. Louis, MO, USA).

Cell culture. The human PC cell lines PANC-1, BxPC-3 and AspC-1, and the human embryonic kidney cell line HEK-293T were obtained from the Type Cell Collection of the Chinese Academy of Sciences (Shanghai, China). PANC-1, BxPC-3 and AspC-1 cells were cultured in RPMI-1640 medium, and HEK-293T in Dulbecco's modified Eagle's medium (DMEM) (Gibco, Grand Island, NY, USA) in a 5\% $\mathrm{CO}_{2}$ and $95 \%$ air humidified atmosphere at $37^{\circ} \mathrm{C}$. All media were supplemented with $10 \%$ fetal bovine serum (Gibco) and $100 \mathrm{U} / \mathrm{ml}$ of penicillin-streptomycin.

Xenograft mouse model. Male nude BALB/c mice (6 week of age) were obtained from the Zhejiang Chinese Medical University Experimental Animal Center (Hangzhou, China), and housed under pathogen-free conditions and were provided with standard laboratory food and water. All animal-handling protocols were approved by the Experimental Animal Use and Management Committee of Zhejiang Chinese Medical University. To induce tumor growth, the right flank of each mouse was subcutaneously injected with $5 \times 10^{6}$ PC BxPC-3 cells suspended in $0.1 \mathrm{ml}$ phosphate-buffered saline (PBS). When subcutaneous tumors developed to $\sim 30 \mathrm{~mm}^{3}$ in size (7 days after inoculation), the mice $(n=24)$ were randomly divided into four groups: a control group (0.9\% saline, i.p. daily), a coix seed emulsion alone group $(12.5 \mathrm{ml} / \mathrm{kg}$, i.p. daily), a gemcitabine alone group (50 mg/kg, i.p. 3/week) and a coix seed emulsion and gemcitabine combination group (coix seed emulsion $12.5 \mathrm{ml} / \mathrm{kg}$, i.p. daily; gemcitabine $50 \mathrm{mg} / \mathrm{kg}$, i.p. 3/week). Body weights and tumor volumes were measured every three days. Tumor volumes were calculated with the formula: Tumor volume $\left(\mathrm{mm}^{3}\right)=$ maximal length $\mathrm{x}$ maximal width $^{2} / 2$. After 24 days of treatment, all mice were overdosed with anesthesia, and tumors were harvested and weighed. The rate of inhibition of tumor growth was calculated using the formula: [(Mean tumor weight of the control group - mean tumor weight of the treatment group)/mean tumor weight of the control group] $x 100 \%$. Tumors tissue were fixed in buffered formalin for further analyses.

Cell viability as detected by MTS assay. Cells were seeded in 96-well microplates at a density of $4 \times 10^{4}$ cells $/ \mathrm{ml}$ and cultured overnight; they were exposed to various concentrations of coix seed emulsion and gemcitabine, alone or in combination for the desired time. Control cells received only dimethyl sulfoxide (DMSO). Cell viability was assessed using the 3-(4,5-dimethylthiazol-2yl)-5- (3-carboxymethoxypheny 1)-(4-sulfophenyl)-2H-tetrazolium (MTS) assay (Promega, Madison, WI, USA) according to the manufacturer's instructions. Cell viability is directly proportional to the absorbance at $490 \mathrm{~nm}$ of a formazan product that is bio-reduced from MTS in living cells as previously described (23). To determine the synergetic effect between coix seed emulsion and gemcitabine, the cells were exposed to drugs in a fixed ratio and the combination index (CI) was calculated by CalcuSyn software (Biosoft, Cambridge, UK). All experiments were carried out in hexaplicate, and were independently repeated at least twice.

Caspase-3 activity assay. Apoptosis of cells after the treatment of coix seed emulsion and gemcitabine, alone or in combination, was evaluated with the use of the Caspase-3/CPP32 Fluorometric Assay kit (BioVision Research Products, Mountain View, CA, USA; according to the manufacturer's instructions), as previously described (23). Cellular lysates (50 $\mu \mathrm{l})$ were extracted and protein concentration was measured using BCA protein assay reagents (Pierce, Rockford, IL, USA). Cleavage of DEVD-AFC, a substrate of caspase-3, was quantified using a fluorescence microplate reader, with $400 \mathrm{~nm}$ excitation and $505 \mathrm{~nm}$ emission filters.

Protein extraction and western blot analysis. Cells were seeded in $100-\mathrm{mm}$ tissue culture dishes and grown to $80 \%$ confluency. Medium was then replaced with fresh medium containing selected drugs at the various concentrations. The control group was treated with the same volume of DMSO. After $48 \mathrm{~h}$, all cells were washed twice with ice-cold PBS, collected in RIPA lysis buffer (20 mM Tris- $\mathrm{HCl}, 150 \mathrm{mM} \mathrm{NaCl}, 1 \% \mathrm{NP}-40$, $5 \mathrm{mM}$ EDTA, $1 \mathrm{mM} \mathrm{Na} \mathrm{VO}_{4}, \mathrm{pH}$ 7.5) supplemented with a protease inhibitor mixture (Sigma-Aldrich, St. Louis, MO, USA), and incubated on ice for $20 \mathrm{~min}$. Afterwards, the cell lysate was centrifuged at $14,000 \mathrm{rpm}$ for $10 \mathrm{~min}$, and the pellet was diluted in SDS-sample buffer. Protein concentration was determined using BCA protein reagents (Pierce). The nuclear and cytoplasmic proteins were extracted with the Nuclear and Cytoplasmic Protein Extraction kit (Pierce; according to the manufacturer's instructions). The cell lysate (30 $\mu \mathrm{g})$ was subjected to electrophoresis on a $4-12 \%$ sodium dodecyl sulfate (SDS)-polyacrylamide gel, and then transferred onto a polyvinylidene difluoride (PVDF) membrane (Bio-Rad, Hercules, CA, USA). Blots were probed with appropriate primary antibodies and IRDye ${ }^{\circledR} 800 \mathrm{CW}$ secondary antibody 
A

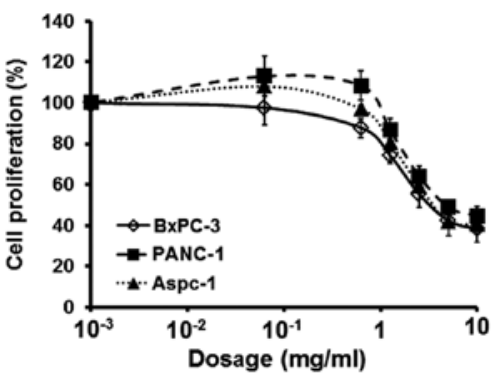

C CSE $\mathrm{mg} / \mathrm{ml}, 72 \mathrm{~h}$

Bcl-2

Cleaved-

PARP

actin
B

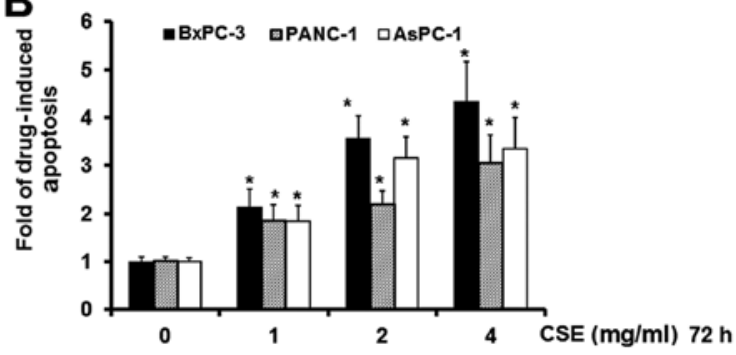

Figure 1. Coix seed emulsion (CSE) dose-dependently inhibits cell proliferation and induces apoptosis of pancreatic cancer cells. (A) BxPC-3, PANC-1 and AsPC-1 cells were treated with CSE $(0-10.0 \mathrm{mg} / \mathrm{ml})$ for $72 \mathrm{~h}$. Data points represent mean \pm SD, $n=3$. (B) Caspase- 3 activity assay of BxPC-3, PANC-1 and AsPC-1 cells after exposure to increasing concentrations of CSE for $72 \mathrm{~h}$. Results are expressed as arbitrary fluorescent units (AFU) normalized to milligram of cytosolic protein. Data are presented as mean \pm SD, n=3. (C) The pro- and anti-apoptosis protein expression levels of BxPC-3, PANC-1 and AsPC-1 cells. Cells were treated with CSE $(0-4.0 \mathrm{mg} / \mathrm{ml})$ for $72 \mathrm{~h}$. Equal amounts of protein $(30 \mu \mathrm{g} / \mathrm{lane})$ were subjected to SDS-PAGE and analyzed by western blotting with specific antibodies to cleaved-PARP, Bax, Bcl-2 and $\beta$-actin. $\beta$-actin served as the internal standard. ${ }^{*} \mathrm{P}<0.05$, treatment vs. the vehicle control. Results are representative of three independent experiments.

(LI-COR Biotechnology, Lincoln, NE, USA). Bands were visualized by Odyssey infrared imaging system (LI-COR Biotechnology) and quantified by densitometry analysis, using ImageJ software (NIH, Bethesda, MA, USA).

Cell transfection and reporter assay. HEK-293T cells (at $70 \%$ confluency) were transfected with the NF-кB-EGFP construct (GeneChem, Shanghai, China), which links an enhanced GFP reporter to an $\mathrm{NF}-\kappa \mathrm{B}$ response element as previously described (16). To prepare DNA for transfection, $10 \mu$ l Lipofectamine 2000 and $2 \mu \mathrm{g}$ DNA were diluted with $0.2 \mathrm{ml}$ of Opti-MEM (both from Invitrogen, Carlsbad, CA, USA), according to the manufacturer's instructions. After incubation for $24 \mathrm{~h}$, the transfection rate was tested (data not shown), and HEK-293T cells for which the transfection rate was $>90 \%$ were treated with the desired concentration of coix seed emulsion alone, with gemcitabine alone, with the coix seed emulsion and gemcitabine combination or with DMSO. After an additional $48 \mathrm{~h}$, the expression of EGFP in each group was captured on a fluorescence microscope system (Olympus, Tokyo, Japan); the cells $\left(1 \times 10^{6}\right.$ cells $\left./ \mathrm{ml}\right)$ were then washed twice with cold PBS, half of them were re-suspended in fixing buffer and analyzed by flow cytometry (Millipore, Billerica, MA, USA) within $1 \mathrm{~h}$. The other half of the cells were lysed and the protein concentration was quantified. Data are reported as the average of three independent experiments.

Electrophoretic mobility shift assay. The electrophoretic mobility shift assay (EMSA) was used to assess NF- $\kappa$ B activation as previously described (24). Briefly, nuclear extracts prepared from cells treated with nuclear and cytoplasmic extraction reagents (Pierce) were incubated with biotin-labeled double-stranded NF- $\kappa$ B oligonucleotide (Beyotime, Beijing, China) for $30 \mathrm{~min}$ at $37^{\circ} \mathrm{C}$, and EMSA was performed, following the instructions in the LightShift Chemiluminescent EMSA kit (Pierce).

Immunohistochemical staining and assessment. Formalinfixed, paraffin-embedded tumor tissues were sectioned (4- $\mu \mathrm{m})$ and incubated with antibodies against $\mathrm{Ki}-67$ and P65, at 1:100 dilutions. All stained slides were examined by an independent observer; and the tissue was assessed for protein expression in neoplastic areas at a magnification of $x 40$. Percentage of Ki-67 and P65 expression was recorded for each area (cytosolic or nuclear), and then averaged for each mouse. A total of five fields were examined in six samples from each of the treatment groups.

Statistical analysis. All data were represented as mean \pm standard deviation (SD) for at least three independent experiments; representative examples are shown. Statistical analysis of multiple group comparisons was performed by one-way analysis of variance (ANOVA). Comparisons between two groups were analyzed using Student's t-tests. A P-value of $<0.05$ was considered to indicate a statistically significant result.

\section{Results}

Coix seed emulsion inhibits the viability and induces the apoptosis of PC cells in a dose-dependent manner. To investigate the cytotoxicity of coix seed emulsion on $\mathrm{PC}$ cell lines in vitro, we exposed BxPC-3, PANC-1 and AsPC-1 cells for $72 \mathrm{~h}$ to coix seed emulsion at increasing concentrations $(0-10.0 \mathrm{mg} / \mathrm{ml})$, and examined the cell viability by the MTS 

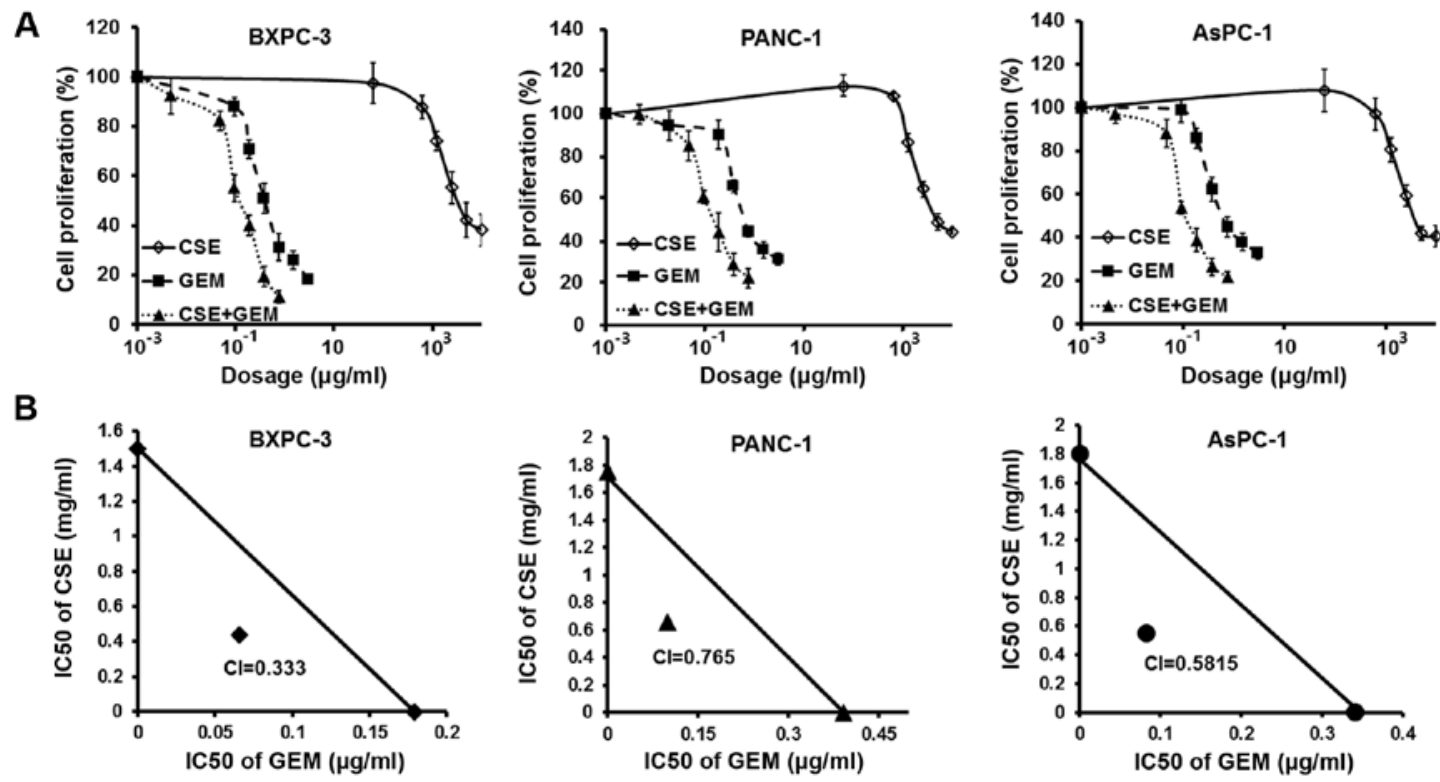

Figure 2. Coix seed emulsion (CSE) enhances the antiproliferation activity of gemcitabine (GEM). (A) BxPC-3, PANC-1 and AsPC-1 cels were pretreated with increasing concentrations of CSE $(0-5.0 \mathrm{mg} / \mathrm{ml})$ for $48 \mathrm{~h}$ and were then treated with CSE and GEM $(0-0.75 \mu \mathrm{g} / \mathrm{ml})$ for $24 \mathrm{~h}$. Grow inhibition was determined by MTS assay. Data points represent mean $\pm S D, n=3$. (B) Isobologram depicted a synergistic effect between CSE and GEM in combination in pancreatic cancer cell lines BxPC-3, PANC-1 and AsPC-1. Results are representative of three independent experiments.

assay. As shown in Fig. 1A, coix seed emulsion exhibited dose-dependent cytotoxicity in the BxPC-3, PANC-1 and AsPC-1 cells with an $\mathrm{IC}_{50}$ value of $1.50,1.75$ and $1.80 \mathrm{mg} / \mathrm{ml}$, respectively.

To further study whether emulsion treatment decreases cell viability through apoptosis, we measured caspase-3 activity in all three cell lines and found that, compared to untreated cells, caspase-3 activity decreased from 1.84 to 4.33 -fold in the treated PC cells, in a dose-dependent manner (Fig. 1B). To clarify the molecular mechanism of coix seed emulsion-induced apoptosis, we determined apoptosis-related protein expression in the BxPC-3, Panc-1 and AsPC-1 cells, and reported that expression of the anti-apoptotic protein Bcl-2 was downregulated, whereas that of the pro-apoptotic protein Bax was upregulated, also in a dose-dependent manner; these findings indicate that the apoptosis-inducing effect of coix seed emulsion can be partly attributed to an altered $\mathrm{Bax} / \mathrm{Bcl}-2$ protein ratio, which is a critical determinant of apoptosis (21). The caspase-3 downstream substrate cleaved-PARP was also increased in the emulsion-treated PC cells. Our results confirm previous studies on the use of coix seed emulsion with breast (25) and liver cancer cells (15). Even though coix seed emulsion does not inhibit the viability of cultured cancer cells as much as do other small molecular inhibitors, it can alter apoptosis signaling in PC cells.

Pretreatment with coix seed emulsion potentiates gemcitabine-induced cytotoxicity. Gemcitabine is the only first-line drug for patients with advanced PC; however it only provides a modest improvement in survival (26), in part due to the development of drug resistance. NF- $\kappa B$ regulation is involved in the formation of such resistance $(27,28)$. Since coix seed emulsion inhibits NF- $\kappa B$ activity in MDA-MB-231 breast cancer cells, we next assessed whether coix seed emulsion enhances the cytotoxicity of gemcitabine in PC cells. We found that pretreatment of coix seed emulsion was more efficacious in sensitizing the cells to gemcitabine compared to co-treatment of the two drugs or whether the emulsion was washed away before adding drugs (data not shown). To confirm synergism between the emulsion and gemcitabine, we pretreated BxPC-3, PANC-1 and AsPC-1 cells with coix seed emulsion alone $(0-5.0 \mathrm{mg} / \mathrm{ml})$ for $48 \mathrm{~h}$, following by co-treatment with varying concentrations of gemcitabine $(0-0.75 \mu \mathrm{g} / \mathrm{ml})$ for another $24 \mathrm{~h}$. Our results showed that pretreatment with coix seed emulsion effectively decreased the $\mathrm{IC}_{50}$ value of gemcitabine from $0.18-0.39$ to $0.066-0.099 \mu \mathrm{g} / \mathrm{ml}$ (Fig. 2A). We then determined $\mathrm{CI}$ values for the combination treatment group. $\mathrm{CI}$ is a quantitative measure of the degree of drug interaction; $\mathrm{CI}<1$ indicates synergism, $\mathrm{CI}>1$ indicates antagonism and $\mathrm{CI}=1$ indicates an additive effect. As shown in Fig. 2B, BxPC-3, PANC-1 and AsPC-1 cells pretreated with coix seed emulsion showed synergistic loss of cell viability, when the pretreatment was combined with gemcitabine ( $\mathrm{CI}=0.333,0.765$ and 0.282 , respectively).

Pretreatment with coix seed emulsion augments apoptosis induced by gemcitabine in PC cells. To confirm whether the enhanced loss of cell viability resulting from pretreatment with coix seed emulsion is mediated by apoptosis, the cells were pretreated $(4.0 \mathrm{mg} / \mathrm{ml})$ with emulsion, followed by gemcitabine. This significantly elicited gemcitabine-induced caspase-3 activity from 1.89- to 2.43-fold, to 7.52- to 8.61-fold $(\mathrm{P}<0.05)$ in all $\mathrm{PC}$ cell lines used (Fig. 3A), suggesting that the loss of viable cells by coix seed emulsion and gemcitabine was due to the induction of the cell death pathway. In agreement with these results, we also found significant upregulation of Bax and downregulation of Bcl-2 protein expression in the combination treatment group (Fig. 3B), and that the combi- 

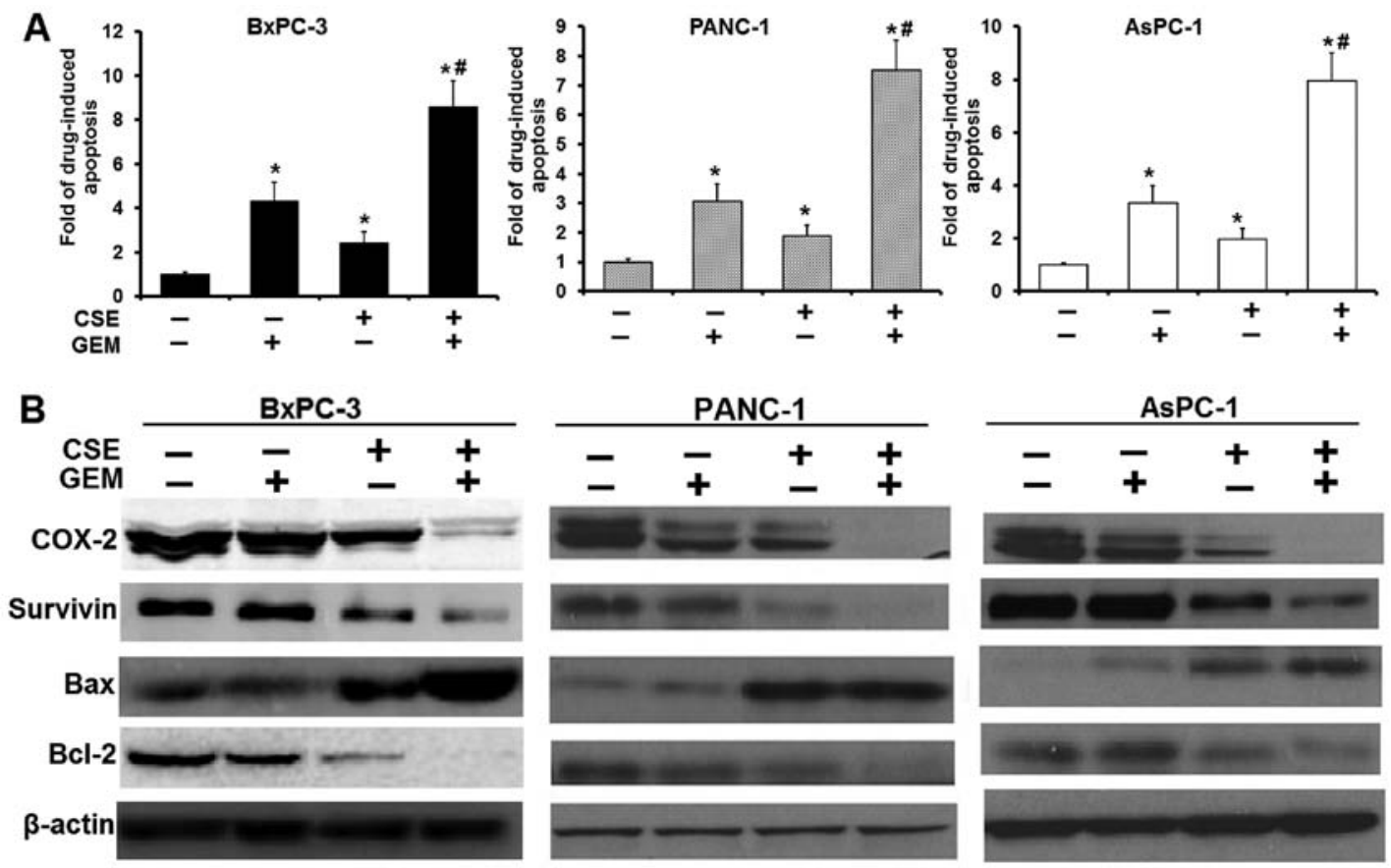

Figure 3. Coix seed emulsion (CSE) and gemcitabine (GEM) combination sensitizes pancreatic cancer cell lines BxPC-3, PANC-1 and AsPC-1 to apoptosis. (A) An induced apoptotic response is shown in the combination groups $(4.0 \mathrm{mg} / \mathrm{ml} \mathrm{CSE}$ for $72 \mathrm{~h}$ and $0.18 \mu \mathrm{g} / \mathrm{ml} \mathrm{GEM}$ for $24 \mathrm{~h})$ relative to the control or monotherapy groups ( $4 \mathrm{mg} / \mathrm{ml} \mathrm{CSE}$ for $72 \mathrm{~h}$ or $0.18 \mu \mathrm{g} / \mathrm{ml} \mathrm{GEM}$ for $24 \mathrm{~h}$, respectively) in pancreatic cancer cells. Results are expressed as arbitrary fluorescent units (AFU) normalized to milligram of cytosolic protein. Data are presented as mean $\pm \mathrm{SD}, \mathrm{n}=3$. (B) NF- $\mathrm{kB}$ regulated downstream pro-survival and anti-apoptotic proteins in pancreatic cancer cells as determined using immunoblotting. Cells exposed to either CSE ( $4 \mathrm{mg} / \mathrm{ml}$ for $72 \mathrm{~h})$ or GEM $(0.18 \mu \mathrm{g} / \mathrm{ml}$ for $24 \mathrm{~h})$ alone or in combination $(4 \mathrm{mg} / \mathrm{ml} \mathrm{CSE}$ for $72 \mathrm{~h}$ and $0.18 \mu \mathrm{g} / \mathrm{ml}$ GEM for $24 \mathrm{~h})$. Equal amounts of protein $(30 \mu \mathrm{g} / \mathrm{lane})$ were subjected to SDS-PAGE and analyzed by western blotting with specific antibodies to Cox-2, survivin, Bax, Bcl- 2 and $\beta$-actin. $\beta$-actin served as an internal standard. ${ }^{*} \mathrm{P}<0.05$, treatment vs. vehicle control; ${ }^{\#} \mathrm{P}<0.05$, combination vs. monotherapy. Results are representative of three independent experiments.

nation treatment significantly suppressed other pro-survival molecules such as survivin and Cox-2. Our results indicate that coix seed emulsion and gemcitabine indeed synergized the cytotoxic effect of gemcitabine on PC cells.

Coix seed emulsion abolishes gemcitabine-induced $N F-\kappa B$ activation and nucleus translocation. Since Bcl-2, survivin and Cox-2 proteins are downstream effectors regulated by NF-kB $(29,30)$, we next assessed the possible mechanistic role of NF- $\kappa \mathrm{B}$ in our experimental system. Employing an

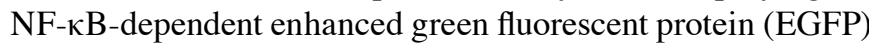
reporter assay, we directly measured the effects of the drugs on a gene promoter element that has a consensus NF- $\mathrm{KB}$ response element in HEK-293T cells. Gemcitabine (0.18 $\mu \mathrm{g} /$ $\mathrm{ml}$ ) treatment alone stimulated the reporter activity; meanwhile coix seed emulsion $(4.0 \mathrm{mg} / \mathrm{ml})$ effectively diminished gemcitabine-induced or non-induced reporter activity (Fig. 4A and $\mathrm{B}$ ). Activation of NF- $\mathrm{KB}$ is associated with translocation to the nucleus of the p65/Rel-A subunit of this transcription factor, as well as with the NF- $\mathrm{BB}$ DNA-binding activity (31). PANC-1 cells were exposed to coix seed emulsion $(4.0 \mathrm{mg} / \mathrm{ml})$ for $72 \mathrm{~h}$, followed by $3 \mathrm{~h}$ of gemcitabine $(0.50 \mu \mathrm{g} / \mathrm{ml})$ treatment; the nuclear and cytoplasmic fractions of the cell lysate were subjected to electrophoresis and immunoblotting by an anti-p65 antibody. Meanwhile, an electrophoretic mobility shift assay was used to assess the NF- $\mathrm{KB}$ DNA-binding activity in the nuclear extracts. Fig. $4 \mathrm{C}$ shows that gemcitabine stimulated the translocation of $\mathrm{p} 65$ from the cytoplasm to the nucleus, consistent with activation of the NF- $\mathrm{BB}$ transcrip- tion factor; this effect was markedly attenuated by treating the cells with coix seed emulsion. These observations were further supported by the finding that coix seed emulsion sequestered the basal level of NF- $\mathrm{BB}$ DNA-binding activity in unstimulated PC cells, and gemcitabine induced NF- $\mathrm{KB}$ DNA-binding activity (Fig. 4D). Our results indicate that the chemosensitizing effect of coix seed emulsion is, in part, due to inactivation of NF- $\mathrm{kB}$ and its downstream genes.

Coix seed emulsion enhances the therapeutic effects of gemcitabine in xenografts derived from Panc-1 cells by inhibiting $N F-\kappa B$ activity. Based on the in vitro finding that pretreatment of coix seed emulsion sensitizes gemcitabineinduced cytotoxicity in PC cells, we evaluated the therapeutic advantage of using coix seed emulsion and gemcitabine in a xenograft nude mouse model implanted with PANC-1 cells (see experimental protocol in Fig. 5A). Relative to the untreated control group, administration of coix seed emulsion by intraperitoneal injection caused a $30 \%$ reduction in tumor weight $(\mathrm{P}<0.05)$, while gemcitabine treatment alone caused a $50 \%$ reduction in tumor volume and weight $(\mathrm{P}<0.05)$ (Fig. 5B and C). However, the combination of coix seed emulsion and gemcitabine demonstrated a $68 \%$ reduction in tumor volume and weight, a result of which was superior to treatment with coix seed emulsion alone $(\mathrm{P}<0.05)$ or gemcitabine alone $(\mathrm{P}<0.05)$ (Fig. 5B and $\mathrm{C})$. Moreover, coix seed emulsion partly rescued the severe weight loss induced in the mice by gemcitabine (Fig. 5D). We additionally investigated whether the coix seed emulsion alone, or in combination 
A

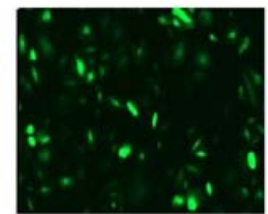

Control

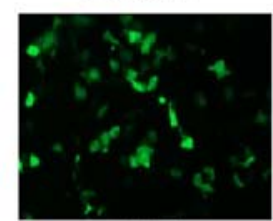

B

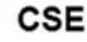

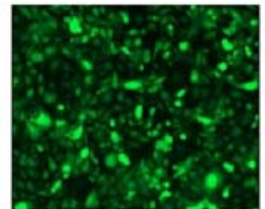

GEM

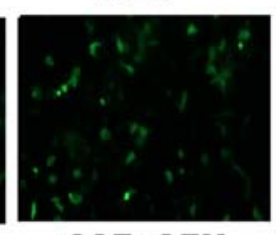

CSE+GEM

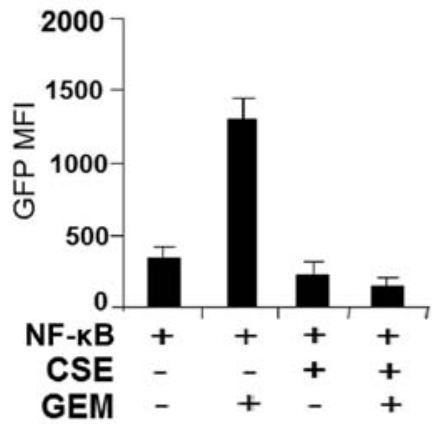

C
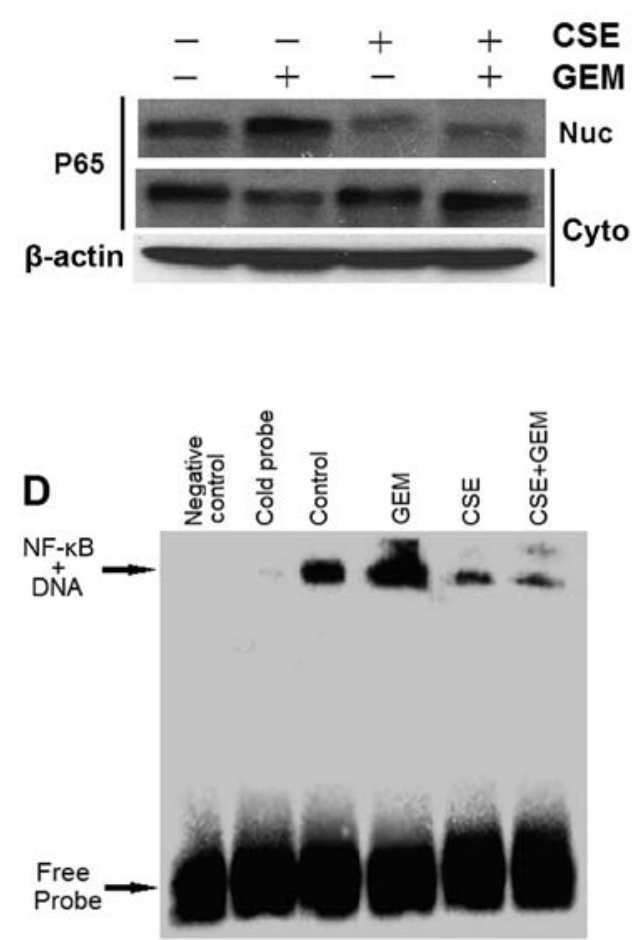

Figure 4. Coix seed emulsion (CSE) suppresses constitutive and gemcitabine (GEM)-induced NF-kB activity. (A) HEK-293T cells were transfected with construct containing the NF- $\mathrm{kB}$ response element that is linked to an enhanced green protein reporter as described in the manuscript. Cells were then treated with CSE $(4.0 \mathrm{mg} / \mathrm{ml}$, for $72 \mathrm{~h})$ and/or GEM $(0.5 \mu \mathrm{g} / \mathrm{ml}$ for $3 \mathrm{~h})$ as shown. The activity of the NF- $\kappa B$ response element was assessed by fluorescence imaging. (B) The fluorescence intensity of the HEK-293T cells which were transfected with the NF- $\kappa$ B reporter was determined by flow cytometry. The drug treatment procedure was the same as described above. The fluorescence intensity was normalized by the protein concentration of each group. Columns represent mean \pm SD. (C) BxPC-3 cells were exposed to CSE $(4.0 \mathrm{mg} / \mathrm{ml})$ for $72 \mathrm{~h}$ and/or GEM $(0.5 \mu \mathrm{g} / \mathrm{ml})$ for $3 \mathrm{~h}$. The cytoplasmic (Cyto) and nuclear (Nuc) fractions of the cells were detected by western blotting using antibodies against p65 and $\beta$-actin. $\beta$-actin served as the cytoplasmic loading control. (D) The DNA-binding activity in the nuclear fraction of BxPC-3 cells in the presence and/or absence of CSE, GEM and the combination as described above. Results are representative of three independent experiments.

with gemcitabine, downregulated NF-kB in the tumor tissue. Immunohistochemistry revealed significant downregulation of p65 expression in groups treated with coix seed emulsion alone $(\mathrm{P}<0.05)$ and with the combination $(\mathrm{P}<0.05)$, compared with the control; only modest alterations were noted in the gemcitabine alone group (Fig. 5E). These findings paralleled the study on a significant reduction in Ki-67 staining in tumors derived from the mice treated with the combination of the two drugs $(\mathrm{P}<0.05)$, indicating diminished cellular viability in the tumors.

Taken together, our in vivo results are consistent with our in vitro findings and collectively provide convincing evidence in support of the superior antitumor efficacy of the combination of coix seed emulsion and gemcitabine.

\section{Discussion}

We demonstrated that coix seed emulsion effectively induces apoptosis by activating caspase- 3 and increasing the $\mathrm{Bax} / \mathrm{Bcl}-2$ ratio in pancreatic cancer (PC) cells; also, that pretreatment of these cells with coix seed emulsion exerts chemosensitization effects that are synergistic with those of gemcitabine.

The major impediments to and challenges of using available treatments for patients with advanced PC are the dose-limiting toxicity to normal tissues $(32,33)$ and the increase in acquisition of drug resistance during gemcitabine-based chemothera- pies (34). Substantial evidence implicates the constitutive activation of the transcription factor NF- $\mathrm{KB}$ in de novo and acquired resistance to the therapeutic response in PC progression $(31,35)$. A possible strategy for overcoming this problem is the use of combinatorial treatments (36); for example, the application of NF- $\kappa B$ inhibitors (37) or natural products (38) to inactive NF- $\mathrm{KB}$ before beginning treatment with conventional therapeutics. Zhou et al (29) recently reported that 6-Shogaol (a phenolic alkanone derived from ginger) potentiates PC to gemcitabine treatment in vitro and in vivo, and that such sensitization is achieved by suppressing the activation signaling via toll-like receptor 4 (TLR4)/NF- $\mathrm{KB}$. We therefore reasoned that coix seed emulsion, an anticancer agent developed from natural products, may similarly serve as a novel chemosensitizing drug, and that its mechanism of action may also be the abrogation of the chemotherapeutic agent-induced activation of NF- $\mathrm{KB}$, which would then inactivate multiple downstream NF- $\mathrm{BB}$-driven survival factors.

Given the robust antitumor activity of the combined use of coix seed emulsion and chemotherapeutic agents in the treatment of different types of cancer, we were interested in ascertaining whether coix seed emulsion is specifically effective in synergistically sensitizing PC cells to chemotherapeutics. Results from a phase II clinical trial (38 patients) in the US showed that patients treated with a combination of coix seed emulsion and gemcitabine had a median progression-free 
A

A BxPC-3 cells

( $5 \times 10^{6}$ cells $\left./ 0.1 \mathrm{ml}\right) \quad$ Gemcitabine, $50 \mathrm{mg} / \mathrm{kg} .3 / \mathrm{wk}$, i.p.

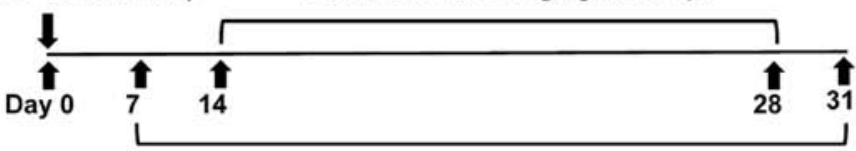

B

Coix seed emulsion, $12.5 \mathrm{ml} / \mathrm{kg}$, daily, i.p.

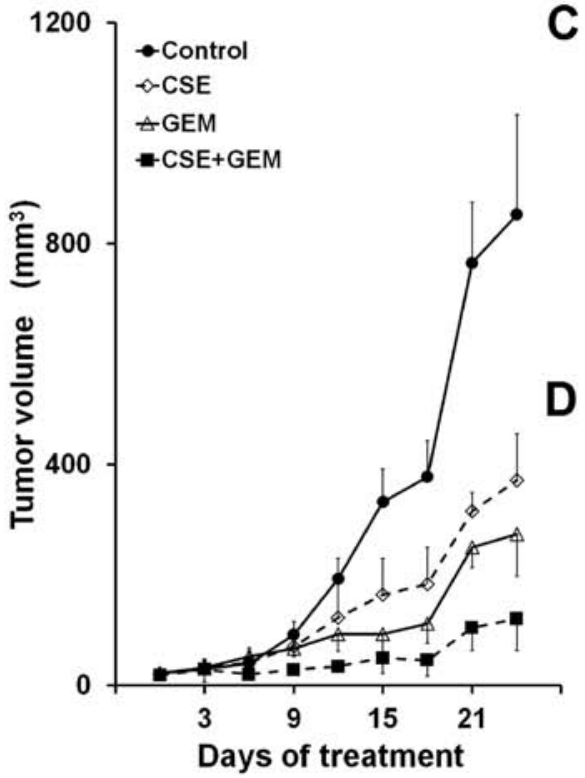

C

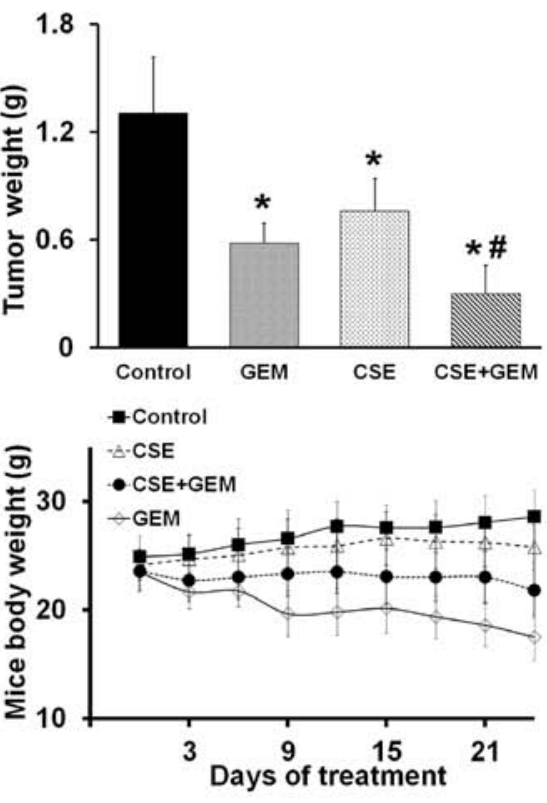

E

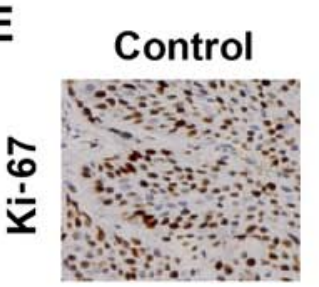

GEM

CSE
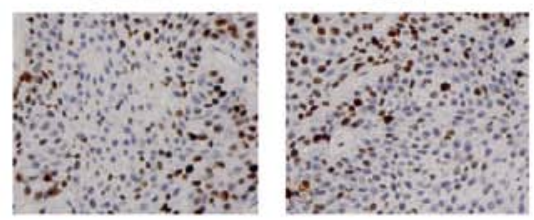

CSE+ GEM
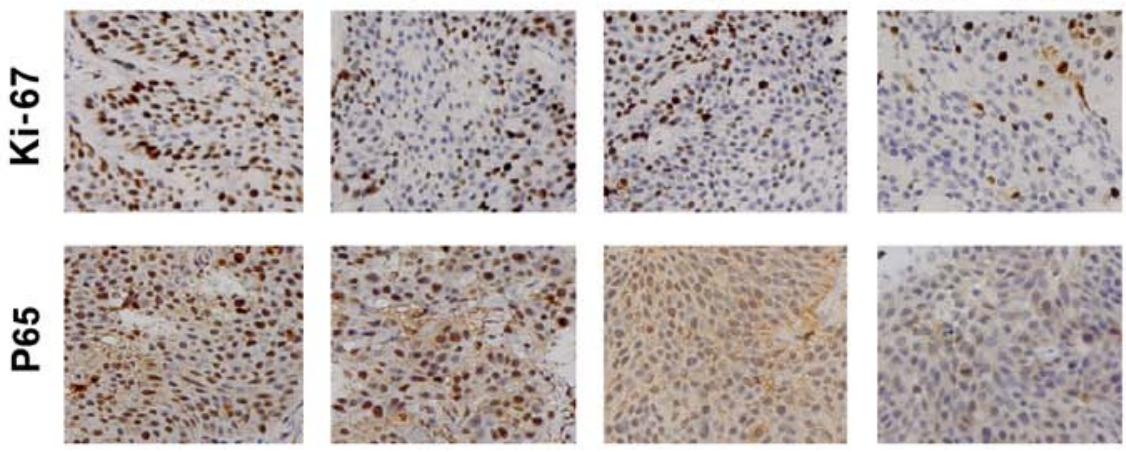

Figure 5. Coix seed emulsion (CSE) potentiates the antitumor effects of gemcitabine (GEM) in BxPC-3 pancreatic cancer xenografts in nude mice. (A) Schematic representation of in vivo experimental protocol. (B) Average tumor volume of vehicle control and drug treatment groups at various time points. Data points represent mean $\pm S D, n=6$. (C) Isolated pancreatic tumor weights of each treatment group were measured after the end-point of the treatment schedule. Columns represent mean $\pm \mathrm{SD}, \mathrm{n}=6$. (D) Body weight alteration of mice from each treatment group. Data points represent mean $\pm \mathrm{SD}, \mathrm{n}=6$. (E) Immunohistochemical analysis results of p65 and Ki-67 protein expression in tumors harvested from pancreatic cancer xenograft mice. " $\mathrm{P}<0.05$, treatment vs. vehicle control; ${ }^{\text {"}} \mathrm{P}<0.05$, combination vs. monotherapy.

survival (PFS) of 114 days, which was significantly longer than the median PFS of 57.5 days in the gemcitabine only group $(\mathrm{P}=0.008)$ (12). In another phase II clinical trial (58 patients) in China, addition of coix seed emulsion to gemcitabine treatment led to a (non-significant) trend towards improved survival of patients with advanced PCs (13). We examined this issue further in our in vitro and in vivo studies. The in vitro experiments showed that treatment with coix seed emulsion alone caused a modest loss of viable PC cells; this effect varied with the cell type used $\left(\mathrm{IC}_{50}=1.50,1.75\right.$ and $1.80 \mathrm{mg} / \mathrm{ml}$ in BxPC-3, PANC-1 and AsPC-1 cells, respectively); however, pretreatment with coix seed emulsion effectively decreases the $\mathrm{IC}_{50}$ value of gemcitabine; we believe that the lower dose may lead to less toxic side-effects on normal cells in vivo. The value of the $\mathrm{CI}$ also confirmed the synergism of coix seed emulsion and gemcitabine combination. Additionally, our results revealed that coix seed emulsion alone is a general inducer of apoptosis in PC, likely due to downregulation of anti-apoptotic Bcl-2, upregulation pro-apoptotic Bax and cleavage of PARP. This is consistent with previous studies that the drug inhibits and activates anti- and pro-apoptotic genes, respectively, in various solid tumors $(39,40)$. Furthermore, we noted that pretreatment with coix seed emulsion elicited significantly higher apoptosis in the PC cell lines tested. We conclude that the synergistic effect of coix seed emulsion and gemcitabine in PC cells may be due to enhanced gemcitabine-induced apoptosis. 
Next, we addressed the molecular mechanisms whereby coix seed emulsion sensitizes PC cells to gemcitabine. Preclinical studies found that coix seed emulsion markedly decreased the level of $\mathrm{NF}-\kappa \mathrm{B}$ in the nucleus in Lewis lung carcinoma (22), and inhibited protein kinase $\mathrm{C} / \mathrm{NF}-\kappa \mathrm{B}$ signaling in a dose-dependent manner in MDA-MB-231 breast cancer cells (16). We thus investigated the expression of anti-apoptotic proteins survivin and Bcl-2, and of the proliferation protein Cox-2, both of which are regulated by $\mathrm{NF}-\kappa \mathrm{B}$ at the transcriptional level and can be inhibited by suppressing $\mathrm{NF}-\kappa \mathrm{B}$ (41). We also studied the expression of the pro-apoptosis protein Bax and survivin, a member of the IAP protein family that is constitutively activated in PCs, and contributes to the development of resistance to the chemotherapeutic response (42); in fact, a direct knockdown of survivin and p65 enhanced the chemosensitivity of PC cells to gemcitabine (30). Our immunoblotting results were consistent with these published findings and document that the coix seed emulsion and gemcitabine combination significantly suppressed the level of expression of survivin in the PC cell lines. Additionally, overexpression of Bcl-2 in PC cells has been reported to contribute to chemoresistance (43). Our findings also demonstrated that the combination of the two drugs effectively downregulated Bcl- 2 expression and elevated Bax expression, which in turn enhanced the apoptosis of the cancer cells. Moreover, constitutively overexpressed Cox-2 has been validated as a promising therapeutic target for reversing chemoresistance in cancer cells (44). Our observations reiterate this potential therapeutic benefit in that coix seed emulsion complements the downregulation of Cox-2 by inhibiting $\mathrm{NF}-\kappa \mathrm{B}$, and increases the chemosensitivity of PC cells. The most common form of NF- $\kappa \mathrm{B}$ is a dimer of RelA (p65) and $\mathrm{NF}-\kappa \mathrm{B} 1$ (p50); in an inactive state, this form is sequestered in the cytoplasm; however, following cellular stimulation, active $\mathrm{NF}-\kappa \mathrm{B}$ translocates into the nucleus, where it binds with specific response elements in DNA sequences to switch on gene transcription (45). Collectively, our observations thus provide multiple lines of evidence that coix seed emulsion attenuates gemcitabine-induced $\mathrm{NF}-\kappa \mathrm{B}$ activation by abrogating gemcitabine-induced activation of $\mathrm{NF}-\kappa \mathrm{B}$ response element, inhibiting gemcitabine associated translocation of the Rel-A/p65 subunit to the nucleus, and reducing the DNA binding activity of $\mathrm{NF}-\kappa \mathrm{B}$.

Our in vivo study was performed in nude mice with subcutaneous BxPC-3 human PC xenografts. When $12.5 \mathrm{ml} / \mathrm{kg}$ coix seed emulsion was administered for 24 days, tumor volumes in the treated group were considerably lower than those in the control group $(\mathrm{P}<0.05)$, confirming the findings that coix seed emulsion contributes to the inhibition of tumor growth in xenograft mouse models that bear various types of solid tumors. Notably, coix seed emulsion also markedly augmented the anticancer efficacy of gemcitabine, when compared to mice treated with gemcitabine alone. Additionally, tumor samples significantly exhibited decreased Ki-67 immunoreactivity (indicating reduced viability of cells in tumors treated with the two drugs), as well as diminished p65 immunostaining in the combination group, supporting the finding of decreased $\mathrm{NF}-\kappa \mathrm{B}$ transcriptional activity. The in vivo results are thus consistent with the in vitro molecular investigations, which clearly support the finding that coix seed emulsion sensitizes
PC cancer cells to gemcitabine treatment by inhibiting the constitutive and gemcitabine-induced activation of NF- $\kappa \mathrm{B}$.

In conclusion, our evidence shows that coix seed emulsion pretreatment synergistically abrogates de novo and acquired resistance to gemcitabine in PC cells. Studies on the molecular mechanism underlying this finding point to suppression of $\mathrm{NF}-\kappa \mathrm{B}$ activity and of its downstream target genes as contributing to the synergistic effect. We recommend that coix seed emulsion be developed as a non-toxic adjuvant to conventional chemotherapeutics for the treatment of patients with advanced PC.

\section{Acknowledgements}

The present study was financially supported by grants from the Natural Science Foundation of China (nos. 81202926, 81303235, 81473434 and 81373982), the Zhejiang Provincial Natural Science Foundation of China (LQ12H29002), the Program for Zhejiang Leading Team of S\&T Innovation (2012R10044_05), the Zhejiang Science and Technology Project (2009C33162), the Research Fund for the Doctoral Program of Higher Education (20113322120001), the Zhejiang Health Science and Technology Project (2011KYA119) and the Zhejiang TCM Science and Technology Project (2008GA009). We sincerely thank Dr Sonal Jhaveri Schneider (Dana-Farber Cancer Institute, Boston, MA, USA) for her advice and assistance with the writing of the manuscript.

\section{References}

1. Wolfgang CL, Herman JM, Laheru DA, Klein AP, Erdek MA, Fishman EK and Hruban RH: Recent progress in pancreatic cancer. CA Cancer J Clin 63: 318-348, 2013.

2. Siegel R, Ma J, Zou Z and Jemal A: Cancer statistics, 2014. CA Cancer J Clin 64: 9-29, 2014.

3. Paulson AS, Tran Cao HS, Tempero MA and Lowy AM: Therapeutic advances in pancreatic cancer. Gastroenterology 144: 1316-1326, 2013.

4. Conroy T, Desseigne F, Ychou M, Bouché O, Guimbaud R, Bécouarn Y, Adenis A, Raoul JL, Gourgou-Bourgade S, de la Fouchardière C, et al; Groupe Tumeurs Digestives of Unicancer; PRODIGE Intergroup: FOLFIRINOX versus gemcitabine for metastatic pancreatic cancer. N Engl J Med 364: 1817-1825, 2011.

5. Von Hoff DD, Ervin T, Arena FP, Chiorean EG, Infante J, Moore M, Seay T, Tjulandin SA, Ma WW, Saleh MN, et al: Increased survival in pancreatic cancer with nab-paclitaxel plus gemcitabine. N Engl J Med 369: 1691-1703, 2013.

6. Qi F, Li A, Inagaki Y, Gao J, Li J, Kokudo N, Li XK and Tang W: Chinese herbal medicines as adjuvant treatment during chemoor radio-therapy for cancer. Biosci Trends 4: 297-307, 2010.

7. Normile D: Asian medicine. The new face of traditional Chinese medicine. Science 299: 188-190, 2003.

8. Li D: The anticancer drug Kang-Lai-Te emulsion for infusion. Vestn Ross Akad Med Nauk 9: 32-37, 2005 (In Russian).

9. Liu X, Yang Q, Xi Y, Yu K, Wang W, Zhao X and Kou X: Kanglaite injection combined with chemotherapy versus chemotherapy alone in the treatment of advanced non-small cell lung carcinoma. J Cancer Res Ther 10 (Suppl 1): S46-S51, 2014.

10. Zhan YP, Huang XE, Cao J, Lu YY, Wu XY, Liu J, Xu X, Xiang J and Ye LH: Clinical safety and efficacy of Kanglaite ${ }^{\circledR}$ (Coix Seed Oil) injection combined with chemotherapy in treating patients with gastric cancer. Asian Pac J Cancer Prev 13: 5319-5321, 2012.

11. Fu F, Wan Y and Wu T; Mulati: Kanglaite injection combined with hepatic arterial intervention for unresectable hepatocellular carcinoma: A meta-analysis. J Cancer Res Ther 10 (Suppl 1): S38-S41, 2014. 
12. Tagliaferri MA, Schwartzberg LS, Chen MM, Camacho LH, Kaplan EH, Arena FP, Bienvenu BJ, North SE, Patel H and Li D: A phase IIb trial of coix seed injection for advanced pancreatic cancer. J Clin Oncol 31 (Suppl): e15023, 2013.

13. Sun Y, Li Y, Qin S, Ma D, Jiao SC, Yu SY, Li J, Liu D, Song D and Li D: A multicenter randomized phase II trial on Kanglaite Injection (KLT) plus gemcitabine hydrochloride (GEM) versus GEM in patients with local advanced and metastatic pancreatic cancer. J Clin Oncol 29 (Suppl): e14510, 2011.

14. Jiang Y, Yuan Q, Huang A and Fang Q: The synergistic mechanism of pemetrexed followed by Kanglaite was due to KLT subsequently inhibiting the pemetrexed-activated MAPK signaling pathway. Clin Lab 61: 1353-1363, 2015.

15. Lu Y, Zhang BY, Jia ZX, Wu WJ and Lu ZQ: Hepatocellular carcinoma HepG2 cell apoptosis and caspase- 8 and Bcl-2 expression induced by injectable seed extract of Coix lacryma-jobi. Hepatobiliary Pancreat Dis Int 10: 303-307, 2011.

16. Woo JH, Li D, Wilsbach K, Orita H, Coulter J, Tully E, Kwon TK, $\mathrm{Xu} \mathrm{S}$ and Gabrielson E: Coix seed extract, a commonly used treatment for cancer in China, inhibits NFkappaB and protein kinase C signaling. Cancer Biol Ther 6: 2005-2011, 2007.

17. Perkins ND: The diverse and complex roles of NF- $\kappa B$ subunits in cancer. Nat Rev Cancer 12: 121-132, 2012.

18. Li F and Sethi G: Targeting transcription factor NF-kappaB to overcome chemoresistance and radioresistance in cancer therapy. Biochim Biophys Acta 1805: 167-180, 2010.

19. Arlt A, Gehrz A, Müerköster S, Vorndamm J, Kruse ML, Fölsch UR and Schäfer H: Role of NF-kappaB and Akt/PI3K in the resistance of pancreatic carcinoma cell lines against gemcitabine-induced cell death. Oncogene 22: 3243-3251, 2003.

20. Qanungo S, Uys JD, Manevich Y, Distler AM, Shaner B, Hill EG, Mieyal JJ, Lemasters JJ, Townsend DM and Nieminen AL: $\mathrm{N}$-acetyl-L-cysteine sensitizes pancreatic cancers to gemcitabine by targeting the NFKB pathway. Biomed Pharmacother 68 $855-864,2014$

21. Banerjee S, Kaseb AO, Wang Z, Kong D, Mohammad M, Padhye S, Sarkar FH and Mohammad RM: Antitumor activity of gemcitabine and oxaliplatin is augmented by thymoquinone in pancreatic cancer. Cancer Res 69: 5575-5583, 2009.

22. Pan P, Wu Y, Guo ZY, Wang R, Wang YJ and Yuan YF: Antitumor activity and immunomodulatory effects of the intraperitoneal administration of Kanglaite in vivo in Lewis lung carcinoma. J Ethnopharmacol 143: 680-685, 2012.

23. Gu M, Yu Y, Gunaherath GM, Gunatilaka AA, Li D and Sun D Structure-activity relationship (SAR) of withanolides to inhibit Hsp90 for its activity in pancreatic cancer cells. Invest New Drugs 32: 68-74, 2014.

24. Banerjee S, Wang Z, Kong D and Sarkar FH: 3,3'-Diindolylmethane enhances chemosensitivity of multiple chemotherapeutic agents in pancreatic cancer. Cancer Res 69: 5592-5600, 2009.

25. Chung CP, Hsu CY, Lin JH, Kuo YH, Chiang W and Lin YL: Antiproliferative lactams and spiroenone from adlay bran in human breast cancer cell lines. J Agric Food Chem 59: 1185-1194, 2011.

26. Oettle H, Post S, Neuhaus P, Gellert K, Langrehr J, Ridwelski K, Schramm H, Fahlke J, Zuelke C, Burkart C, et al: Adjuvant chemotherapy with gemcitabine vs observation in patients undergoing curative-intent resection of pancreatic cancer: A randomized controlled trial. JAMA 297: 267-277, 2007.

27. Arlt A, Vorndamm J, Müerköster S, Yu H, Schmidt WE, Fölsch UR and Schäfer H: Autocrine production of interleukin 1beta confers constitutive nuclear factor kappaB activity and chemoresistance in pancreatic carcinoma cell lines. Cancer Res 62: 910-916, 2002.

28. Cao LP, Song JL, Yi XP and Li YX: Double inhibition of NF-kB and XIAP via RNAi enhances the sensitivity of pancreatic cancer cells to gemcitabine. Oncol Rep 29: 1659-1665, 2013.
29. Zhou L, Qi L, Jiang L, Zhou P, Ma J, Xu X and Li P: Antitumor activity of gemcitabine can be potentiated in pancreatic cancer through modulation of TLR4/NF- $\kappa \mathrm{B}$ signaling by 6 -shogaol. AAPS J 16: 246-257, 2014.

30. Liu J, Ma J, Wu Z, Li W, Zhang D, Han L, Wang F, Reindl KM, $\mathrm{Wu} \mathrm{E}$ and $\mathrm{Ma} \mathrm{Q}:$ Arginine deiminase augments the chemosensitivity of argininosuccinate synthetase-deficient pancreatic cancer cells to gemcitabine via inhibition of NF- $\kappa \mathrm{B}$ signaling. BMC Cancer 14: 686, 2014.

31. Maier HJ, Schmidt-Strassburger U, Huber MA, Wiedemann EM, Beug $\mathrm{H}$ and Wirth T: NF-kappaB promotes epithelialmesenchymal transition, migration and invasion of pancreatic carcinoma cells. Cancer Lett 295: 214-228, 2010.

32. Neoptolemos JP, Stocken DD, Friess H, Bassi C, Dunn JA, Hickey H, Beger H, Fernandez-Cruz L, Dervenis C, Lacaine F, et al; European Study Group for Pancreatic Cancer: A randomized trial of chemoradiotherapy and chemotherapy after resection of pancreatic cancer. N Engl J Med 350: 1200-1210, 2004.

33. Stathis A and Moore MJ: Advanced pancreatic carcinoma: Current treatment and future challenges. Nat Rev Clin Oncol 7: 163-172, 2010.

34. Chiorean EG and Coveler AL: Pancreatic cancer: Optimizing treatment options, new, and emerging targeted therapies. Drug Des Devel Ther 9: 3529-3545, 2015.

35. Carbone $\mathrm{C}$ and Melisi D: NF- $\mathrm{kB}$ as a target for pancreatic cancer therapy. Expert Opin Ther Targets 16 (Suppl 2): S1-S10, 2012.

36. Wang Z, Li Y, Ahmad A, Banerjee S, Azmi AS, Kong D and Sarkar FH: Pancreatic cancer: Understanding and overcoming chemoresistance. Nat Rev Gastroenterol Hepatol 8: 27-33, 2011.

37. Nakanishi $\mathrm{C}$ and Toi $\mathrm{M}$ : Nuclear factor-kappaB inhibitors as sensitizers to anticancer drugs. Nat Rev Cancer 5: 297-309, 2005.

38. Luqman S and Pezzuto JM: NFkappaB: A promising target for natural products in cancer chemoprevention. Phytother Res 24: 949-963, 2010

39. Lu Y, Li CS and Dong Q: Chinese herb related molecules of cancer-cell-apoptosis: A minireview of progress between Kanglaite injection and related genes. J Exp Clin Cancer Res 27: 31, 2008.

40. Liu Y, Zhang W, Wang XJ and Liu S: Antitumor effect of Kanglaite ${ }^{\circledR}$ injection in human pancreatic cancer xenografts. BMC Complement Altern Med 14: 228, 2014.

41. Hill R, Li Y, Tran LM, Dry S, Calvopina JH, Garcia A, Kim C, Wang Y, Donahue TR, Herschman HR, et al: Cell intrinsic role of COX-2 in pancreatic cancer development. Mol Cancer Ther 11: 2127-2137, 2012

42. Jiang C, Tan T, Yi XP, Shen H and Li YX: Lentivirus-mediated shRNA targeting XIAP and survivin inhibit SW1990 pancreatic cancer cell proliferation in vitro and in vivo. Mol Med Rep 4: 667-674, 2011.

43. Dong J, Zhao YP, Zhou L, Zhang TP and Chen G: Bcl-2 upregulation induced by miR-21 via a direct interaction is associated with apoptosis and chemoresistance in MIA PaCa-2 pancreatic cancer cells. Arch Med Res 42: 8-14, 2011.

44. Ali S, Banerjee S, Schaffert JM, El-Rayes BF, Philip PA and Sarkar FH: Concurrent inhibition of NF-kappaB, cyclooxygenase-2, and epidermal growth factor receptor leads to greater anti-tumor activity in pancreatic cancer. J Cell Biochem 110: 171-181, 2010.

45. Li L, Aggarwal BB, Shishodia S, Abbruzzese J and Kurzrock R: Nuclear factor-kappaB and IkappaB kinase are constitutively active in human pancreatic cells, and their down-regulation by curcumin (diferuloylmethane) is associated with the suppression of proliferation and the induction of apoptosis. Cancer 101: 2351-2362, 2004. 